\title{
The business value of information system-enabled e-collaboration capabilities
}

\begin{abstract}
This study aims to understand how firms in developing countries can effectively use their Information System (IS) resources to develop valuable e-collaboration capabilities that in turn improve business performance. A questionnaire-based survey was conducted to collect data from 408 Iranian and Malaysian manufacturing firms. Findings revealed that Supply Chain-Wide Process Integration (SCPI) and Collaborative Knowledge Management (CKM) are key IS-enabled capabilities that enhance performance gain of manufacturing firms. The work found that these capabilities serve as catalysts in transforming the value of IS resources controlled by firms into business performance improvement. The results suggest that SCPI, as a determinant of a highly integrated and dynamic supply chain, is an important intermediate organizational capability through which value of IS resources can be materialized. Likewise, the findings imply that CKM across a given supply network, as a valuable intermediate organizational capability, converts the benefits of both technical and human IS resources into performance gain at the corporate level.
\end{abstract}

Keyword: Business performance; Collaborative supply chain management; Developing countries; Information system; Knowledge management; Resource-based view; Supply chain process integration 